\title{
PERFORMANCE TESTS OF RADIO SYSTEM OF LANDING AIDS
}

\author{
By H. Diamond
}

\section{ABSTRACT}

Details are given the final stage of development of the Bureau of Standards system of radio landing aids designed to assist aircraft in making safe landings during fog or other conditions of low or zero visibility. Results of the first stage of the work which consisted of fundamental experiments and research to develop the basic component parts of the system, including a runway localizing beacon, a landing beam, marker beacons, and suitable radio receiving and indicating apparatus for use in the air, were described in this Journal in October 1930 (RP238). The final stage of the work comprised the practical development of the component parts and fitting them together to form a workable system capable of ready coordination with existing and projected aeronautical radio aids. Changes in engineering design of the component parts, necessitated by practical considerations of the use of the system, are described. Important examples of such changes include expansion of the system to take care of wind direction, redesign of the landing beam transmitting antenna array to provide greater control of the horizontal and vertical directivity of the beam, development of a more flexible marker beacon and antenna system, design of a more practicable receiving system, and coordination in a single instrument of the course indications used for lateral and vertical guidance.

Performance data are given on the operation of the system over an extended period of time, which indicate its complete practicability for commercial use. The tests on the system were conducted in two phases. The first, at College Park, Md., consisted of demonstrating the practicability of the system by means of an extensive series of hooded 'landings. The second phase involved the testing of the complete system under the conditions obtaining at a busy commercial airport. An installation was made, in cooperation with the city of Newark, at the Newark Municipal Airport, Newark, N.J. During several months of tests at Newark, besides making a large number of hooded landings, it was possible to fly at all times when all other airplanes were on the ground because of fog. The operation of the system was demonstrated in the air to many engineers and officials as well as to nearly one hundred air transport pilots. Perhaps the most striking demonstration consisted of a completely blind flight from College Park, Md., to the Newark airport, during which radio was the sole means used for directional guidance and for landing.

\section{CONTENTS}

I. Introduction

II. General description of the system

III. Practical application of the system

1. Runway localizing beacon

2. Landing beam

3. Marker beacons

4. Monitoring and communication system

5 . Coordination of receiving and indicating equipment

IV. Operation of the system

1. Method of making a landing during fog

2. Use of system in event of failure of one of its elements .....

3. Simplification of system for economy purposes........

V. Performance data and tests

1. Tests at College Park, M $\mathrm{d}$

2. Demonstrations and tests at Newark, N.J.

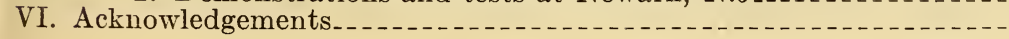




\section{INTRODUCTION}

Research work on a radio system for landing aircraft during zero visibility, carried on in the Research Division of the Aeronautics Branch of the Department of Commerce, at the Bureau of Standards, during 1928 to 1930, was described in the October 1930 issue of this Journal. ${ }^{1}$ The work covered the first stage of development of the system, comprising fundamental experiments and research to develop tools for attacking the problem. The runway localizing beacon, the landing beam, and the marker beacon, constitute these tools. The present paper describes the final stage of the development, consisting of improvement of these tools; fitting them together to form a complete and workable system at both the transmitting and receiving ends; and, finally, demonstrating the practicability of the system by means of hooded landings and by flights and landings at a commercial airport under conditions of visibility causing complete interruption of all other flying.

\section{GENERAL DESCRIPTION OF THE SYSTEM}

Prior to analyzing the results achieved during the final stage of this project, it is desirable to review briefly the problems incidental to the "instrument" landing of aircraft and how the radio system of landing aids provides a solution to these problems. To land an aircraft safely at an airport completely blanketed by fog, it is necessary for the pilot, $(a)$ to find the vicinity of the airport, and $(b)$ to find and reach a suitable point of landing. The radio range-beacon system now in use on the civil airways of the United States renders the solution of the first phase of the problem an accomplished fact. The pilot following the beacon signals is guided directly over the beacon station (which is located within a few miles of the airport), and thereby learns his exact position with respect to the airport. The second phase of the problem requires information on the position of the landing aircraft in three dimensions. Lateral and longitudinal guidance are required to determine the direction of landing and the boundaries of the landing field, while vertical guidance is necessary for the determination of altitude and of the freedom of the landing path from obstacles. In the system of radio landing aids three elements are utilized to give the necessary guidance in three dimensions.

The runway localizing beacon gives indications of the lateral position of the aircraft with respect to the airport and permits keeping the aircraft directed to and over the desired landing runway. A 200watt transmitting set of the visual beacon type, operating in the beacon range of frequencies (200 to $400 \mathrm{kc}$ ) and feeding two small, multi-turn loop transmitting antennas, is employed. One of the beacon courses produced is oriented to coincide with the desired landing direction, depending on the wind conditions. On the aircraft the receiving set normally used by air transport operators for the reception of radio range-beacon signals and airways weather broadcasts is employed for receiving the runway-beacon signals. This set is supplemented by a reed converter ${ }^{2}$ to convert the beacon signals to

\footnotetext{
${ }^{1} \mathrm{H}$. Diamond and F. W. Dunmore, A Radiobeacon and Receiving System for the Blind Landing of Aircraft. B.S. Jour. Research, vol. 5 (RP238), page 897, October 1930.

2 F. W. Dunmore, A Course Indicator of Pointer Type for the Visual Radio Range-Beacon System. B.S. Jour. Research, vol. 7 (RP 336), p. 147, July 1931; Proc. I.R.E., vol. 19, p. 1579, 1931.
} 


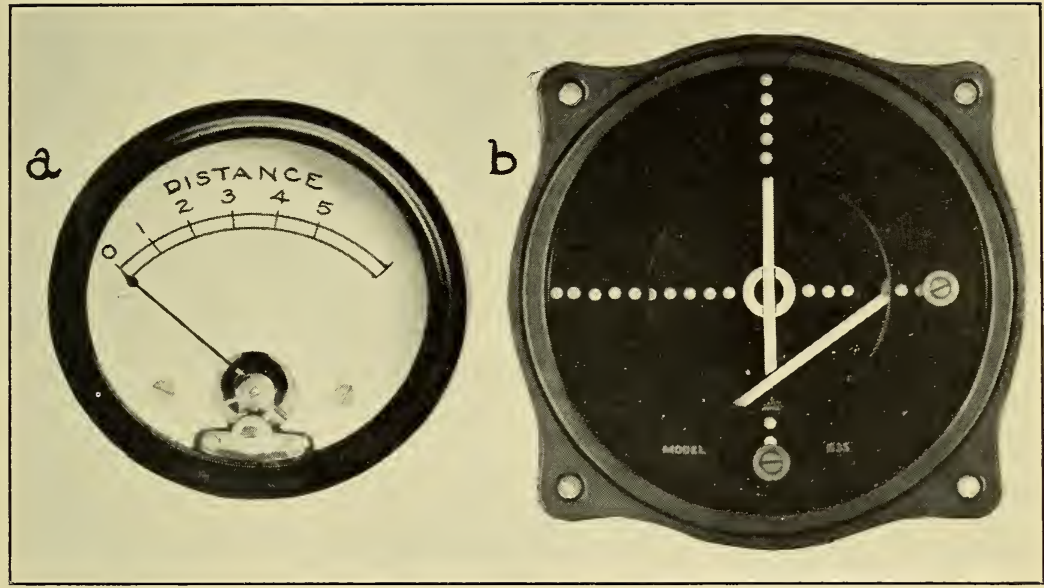

FIGURE 1.-Indicating instruments required on the aircraft for utilizing the radio system of landing aids.

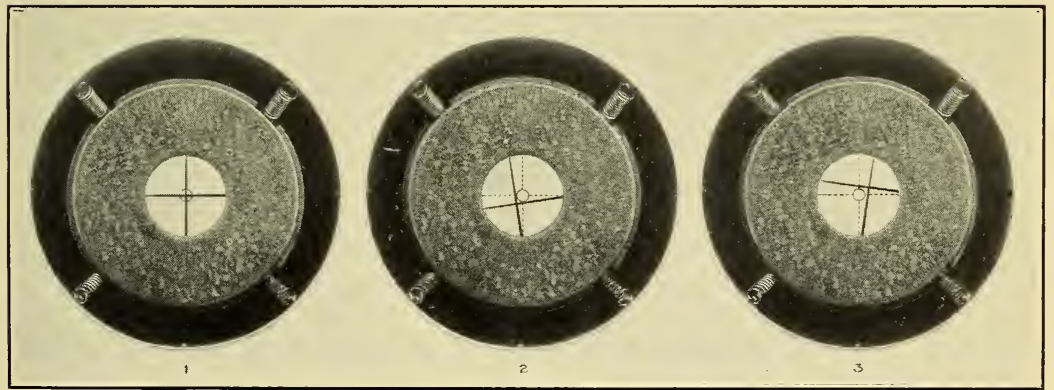

Figure 2.-Typical course indications with combined instrument.

1. Aircraft on proper spatial landing path; 2, aircraft to the left of desired landing direction and too low; 3 , aircraft to the right of desired landing direction and too high. 
pointer type course indications, and also by an automatic volume control unit ${ }^{3}$ whose function is to relieve the pilot of the burden of continuously adjusting the sensitivity of the receiving set as the distance between the aircraft and the ground station changes. The course indicator consists of the vertical pointer of a combined instrument shown in figure $1(a)$. This pointer is pivoted about its lower end and swings left or right of a vertical index line depending upon whether the aircraft is on one side or the other of the runway course. A reversing switch is provided so that the deflection of the pointer and the direction of deviation of the aircraft coincide whether the aircraft is flying away from or toward the beacon.

Vertical guidance of the aircraft is given by a horizontally polarized ultra-high-frequency landing beam directed at a small angle above the horizontal and used in such a way as to provide a very convenient gliding path for the landing aircraft. The frequency of operation is 90,800 kilocycles (3.3 meters).

On the aircraft a simple ultra-high-frequency receiver is used, fed by a transmission line from a horizontal half-wave receiving antenna which is located in the wing slightly ahead of the leading edge. The rectified output from this receiving set operates the horizontal pointer of the combined instrument shown in figure $1(a)$. The receiver sensitivity is so adjusted that the line of constant received signal below the inclined axis of the beam, corresponding to half-scale deflection of the horizontal pointer, marks out a landing path which is suitable for the aircraft and airport considered. The horizontal index line across the face of the combined instrument represents the point of half-scale deflection and corresponds to the proper landing path. The horizontal pointer represents the position of the aircraft relative to this path. A rise of this pointer above the horizontal index line indicates that the aircraft is above the proper landing path, while the reverse is true if the pointer falls below the index line.

Consideration of the operation of the combined instrument will show that the point of intersection of the two pointers represents the position of the aircraft relative to the desired landing runway and the proper landing path. Figure 2 shows three typical readings on the combined instrument. The coordination of the two sets of course indications into a single reading is of utmost importance to the pilot, relieving him of the need for considerable mental effort. Deviations from both courses may be corrected simultaneously. By keeping the pointers crossed over the small central circle on the instrument face, a suitable spatial landing path is followed down to the point of landing.

Longitudinal position of the aircraft as it approaches the airport is given by the combination of a distance indicator on the aircraft with the aural signals received from two marker beacons. The distance indicator, see figure $1(b)$, consists simply of a direct-current milliammeter connected in the plate supply to the radio-frequency amplifying tubes of the beacon receiving set. Since the automatic volume control operates to increase the negative biasing voltage on the grids of these tubes with increasing input voltages to the receiving set, the plate current is approximately inversely proportional to the field intensity of the runway beacon. The instrument may therefore be calibrated in miles from the beacon (say, 0 to 5 miles). The

\footnotetext{
3 W. S. Hinman, Jr., Automatic Volume Control for Aircraft Radio Receivers. B.S. Jour. Research, vol. 7 (RP 330), p. 37, July 1931.
} 
distance indication secured is approximate only, but is sufficiently accurate for all necessary maneuvers of the landing aircraft at distances from the airport of the order of 1 to 5 miles.

Absolute indication of the longitudinal position of the aircraft when near the airport is given by aural signals from two low-power markerbeacon transmitters. One marker beacon is located about 2,000 feet from the approach end of the airport while the other marker defines the boundary or edge of the landing field. Different modulation frequencies are employed for the two marker beacons to facilitate ready identification of the one being passed over; the marker beacon at the field boundary having a modulation of about 250 cycles and the approach marker beacon a modulation of 1,250 cycles. The marker beacon transmitting antennas provide for great flexibility of operation; any portion of the landing field boundaries and approaches may be defined, and any radio frequency may be used in the range of from 200 to 20,000 kilocycles. These features will be discussed in more detail in section III.

\section{PRACTICAL APPLICATION OF THE SYSTEM}

The foregoing description outlines the general principles underlying the operation of the system. A number of practical problems arise in the application of these principles to provide a workable transmitting and receiving set-up. These problems have influenced to considerable extent the engineering design of the component elements of the system. To facilitate discussion of the engineering factors involved, repeated reference will be made to the experimental installation of the landing system at the Newark Municipal Airport, Newark, N.J. A three-dimensional view showing the layout of the ground transmitting equipment at Newark is given in figure 3.

\section{RUNWAY LOCALIZING BEACON}

The question of location at a given airport of the runway localizing beacon transmitter and antennas is related to the number of landing directions it is desired to serve, which, in turn, depends upon the prevailing wind directions during conditions of low visibility. If it is desired to provide for all wind directions so that an aircraft may land into the wind under all conditions, several expedients are available.

One arrangement is to mount the transmitter, antennas, and power supply, on a truck and to furnish service into the wind by moving the truck to the proper position just off the field. This method is not economical since special design features are required in the equipment. Moreover, a major objection is that the runway beacon service is interrupted between changes of truck location. Such factors as snow, ice, tire trouble, engine trouble, traffic, and inaccessibility of the truck position corresponding to certain wind directions, may make this interruption somewhat lengthy.

A second arrangement is to locate the loop transmitting antennas in the center of the airport in a pit provided with sturdy roof construction level with the surface of the airport so that an airplane may roll over it. The transmitter may also be located in the pit or may preferably be installed in a location more convenient for maintenance and operation. In the latter case, radio-frequency power is fed to the loop antennas by means of buried transmission-line cables. The 
installation may be operated as a 4-course beacon with the four courses aligned to coincide with four major runway directions, or it may be used as a beacon giving two $180^{\circ}$ courses, one of which may be oriented into the wind at all times, either by remote control from the operations office or automatically. The operation of the runway beacon underground has been tested and found satisfactory. An experimental pit installation was made at College Park for these tests. The distance range was reduced by about 50 percent from that obtained with the runway beacon above ground; the courses were found to be well defined and somewhat sharper than for above-ground operation.

A third arrangement is to place the runway beacon in any convenient location and to provide a buried transmission-line system whereby radio-frequency power may be fed to one or the other of two loop-antenna systems, each located just off the airport in line with a major runway direction. Transmission lines of the order of several thousand feet in length may be employed without undue loss of power. By strategically locating the two sets of loop antennas, practically all wind directions may be served. This method provides the most economical and efficient means for taking care of all wind directions.

At most airports, it is not expected that it will prove necessary to serve more than one landing direction. A study of meteorological data for a number of airports has shown that the wind during low visibility conditions generally comes from one major direction. The following data summarizes the conditions for the Newark airport during the period July 1, 1930, to June 30, 1931. Ceilings under 1,000 feet were observed 740 times; the wind was calm 25 times; north 128 times; northeast 291 times; east 107 times; southeast 67 times; south 34 times; southwest 57 times; west 16 times; northwest 15 times. Thus, for all ceilings below 1,000 feet, the prevailing wind direction was from the northeasterly quadrant. Accordingly, the runway beacon is located at the northeast end of the Newark airport and one of the courses is oriented along the northeast-southwest runway. In this installation, the loop antennas are housed in the same building as the transmitting set to provide protection from the elements. Each antenna consists of 7 turns of no. 10 wire wound on a wooden frame 12 feet long by 10 feet high, with a 2-inch spacing: between turns. A goniometer is provided to swing the course anywhere between the two hangar lines, thereby giving service over a sector of approximately $40^{\circ}$.

To secure a true picture of the percentage of time, during low visibility, when the Newark runway beacon is useful, it is necessary to consider two other factors in addition to the data on wind directions given in the foregoing paragraph. The first is that for ceilings above 100 feet, the landing system may be used regardless of wind direction. A pilot breaking through this ceiling finds himself at the southwest approach to the field; from that point he may maneuver the aircraft (underneath the ceiling) to land in any desired direction. The second factor is that, as the ceiling becomes progressively lower than 1,000 feet, the wind velocity becomes correspondingly lower so that, finally, at ceilings of 100 feet or lower, the wind velocity rarely exceeds 6 to 8 miles per hour. Under these conditions, landings may be made downwind or crosswind if required. It is thus evident that a 1-direction runway beacon service, if properly oriented, is sufficient for all 
practical purposes. As a matter of fact, during several months of tests at Newark, it was found unnecessary to use the goniometer for swinging the course in the $40^{\circ}$ sector between the hangar lines. Fixed orientation along the northeast-southwest runway was found preferable, since the fixed courses and quadrants could then be employed for fixing definitely the position of the aircraft with respect to the airport during blind flights. In the case of airports located at a considerable distance from airway radio range beacons, this constitutes an important feature in finding the airport.

Other details to be considered in connection with the runway localizing beacon are: radio frequency; required sharpness of the course; and the effect of power lines, railroad tracks, and the like, upon the straightness of the course. The radio frequency on which the runway beacon operates should be at one end or the other of the beacon band, so that its signals may be received on the beacon receiving set carried aboard aircraft and at the same time a minimum of interference be had from nearby 2-kilowatt airway radio range beacons. The Federal Radio Commission has proposed setting aside the frequency, 224 kilocycles, for this service at all airports; this frequency fulfills the above requirements.

In the course of prolonged tests on the system, it was found desirable to provide a very sharp runway beacon course in order to keep the aircraft as accurately as possible along the desired landing direction and thereby to clear obstructions in the approach to the airport. This was particularly true in the experiments at College Park, Md., where the approach is quite restricted. The width of a radiobeacon course becomes progressively less as the beacon is approached. When the course was adjusted to the desired sharpness at a fow miles from the airport, it became quite difficult for the pilot to follow the course at close range to the beacon. Once off the course, an attempt to get back on would result in overcompensation or "hunting" about the course, which would become progressively worse until finally the pilot could no longer follow the course. Two means were adopted to overcome this difficulty. The first consisted of utilizing a directional receiving antenna on the aircraft, the directivity being secured through the addition to the usual vertical pole antenna of a flat-top element running back to the vertical rudder fin. See figure 4. The antenna is then equivalent to an inclined receiving antenna with backward inclination. The directional effect is observed when flying at an angle to the course. Upon turning into the course there is an apparent moving of the course toward the airplane. The reverse is true when turning away from the course. The net result is to provide automatic compensation for the pilot's tendency to "hunt" or "weave" about the course. The second means adopted was to use the vertical pointer of the combined instrument simply as a check instrument, the primary instrument depended upon to determine the directional heading of the aircraft being the compass, preferably of the gyroscopic type. When the vertical pointer shows that the aircraft has deviated from the runway course, the compass bearing is altered to provide gradual return to the course. After several corrections, the proper compass bearing is determined which will provide just the proper angle of "crab" into the wind to maintain the aircraft along the desired course. It is important to note that the angle of correction for wind drift is thereby also determined, this angle being equal to the difference 


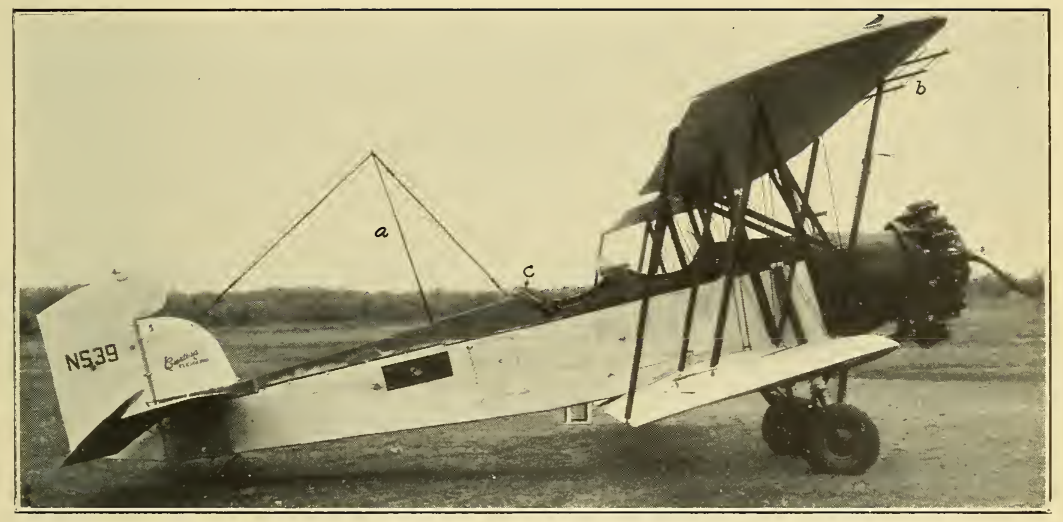

FiguRE 4.-Airplane used in landing tests.

$a$, Beacon receiring antenna; $b$ landing beam receiving antenna; $c$, hood for blind landings. 

between the compass bearing required to keep the aircraft on the runway course minus the true compass bearing of the runway. The use made of this correction angle will be described in section IV.

A direction finder on the aircraft, with bilateral pointer-type course indication, has been suggested for use in landing in place of the runway beacon method outlined in the foregoing description and has been tried with considerable success by personnel of the U.S. Air Corps at Wright Field, Dayton, Ohio. An advantage is that the direction finder indicates the directional heading of the aircraft at all times, thereby obviating such difficulties as "hunting" about the runway beacon course. Other factors of use counterbalance this advantage, however, as will appear from the following. The aircraft is oriented along the proper runway direction by means of direction finder bearings on two fixed ground stations lined up with the runway, and the signals from one of these stations (the one nearer the airport), utilized for direction indication. Wind drift is detected when check bearings on the other ground station show that the aircraft is off course. Correction is made by changing the orientation of the direction-finder loop antenna and, after following the course indications of the first station for an appreciable period, taking a check bearing on the second station. That orientation of the loop antenna is chosen which gives "on-course" readings for the second station. The angle between the new position of the loop antenna and its original position (perpendicular to the longitudinal axis of the aircraft) is equal to the drift angle. For the new loop antenna position, indications from either ground station give the true runway direction provided, of course, that the wind direction and velocity remains unchanged. The bearing of the airplane compass is now noted. Once the glide is started for descent of the aircraft to the landing surface, it is not feasible to keep taking check bearings on the second ground station to determine if wind drift due to changes in wind direction or velocity is taking place. Close check of the airplane compass bearing is required for this purpose, wind drift being observed by a departure of the compass bearing from the value noted. Two instruments are therefore utilized, as in the case of the use of the runway beacon, while a somewhat more involved procedure for determining the true runway direction is required. In actual use, at Wright Field, of this method of runway direction indication, considerable simplification of the above procedure for determining the true runway direction has been found feasible. This is made possible by suitable location of the ground station nearer the airport, the distance of this station from the airport boundary being the important factor. The direction-finder bearings on this station guide the aircraft directly over it, even if wind drift correction is not properly made. Upon arriving over the station, the pilot swings the aircraft so that the compass bearing corresponds to the proper runway direction. If the distance from the airport is not too great, this is sufficient for landing on the runway in spite of cross winds. With this simplification, the use of the direction-finder method becomes comparable with the runway-beacon method for determining the runway direction. Both methods require checking the compass bearing against the radio course indicator. The choice appears to be based on what additional receiving equipment is required on the aircraft. Since practically all commercial transport airplanes carry beacon-receiving equipment, the runway-beacon method is preferable for transport use. 
The runway course as defined by either the runway beacon or a direction finder may depart considerably from a straight line due to the presence of long conductors such as telephone and power lines and railroad tracks. The photographic strip of the terrain at College Park shown in figure 5 illustrates this effect. The runway localizing beacon is located at $(a)$, and a course oriented in the direction indicated by the three radiating black lines. The true course as determined by numerous flights over a period of many months is actually as shown by the white line. The general bow in the course toward the railroad between points $(b)$ and $(c)$ may be attributed to the effect of the railroad tracks and telephone lines running parallel to the tracks. The bend in the reverse direction, at $(d)$, is apparently caused by the power lines running transversely to the course. It is interesting to note that the bend $(c)$, because of its proximity to the airport, gave considerable difficulty during hooded landing tests by causing exaggerated "hunting" about the course just prior to the final landing maneuvers. The adoption of the directional receiving: antenna produced a tremendous reduction in troubles from this effect.

The sensitivity of the vertical pointer motion of the combined instrument has been made dependent on the sharpness of course required. The vertical movement of the instrument shown in figure 1 (a) is adjusted to give half-scale deflection on either side of zero for a third of the current required for full-scale deflection. A high degree of sensitivity and attendant course sharpness is thereby maintained about the "on-course" position, while for large deviations "offcourse" the sensitivity decreases to permit keeping the deflection within the range of the instrument. The latter feature is valuable when maneuvering about the beacon. Sufficient damping of the instrument pointers is obtained by the use of cobalt chrome magnets, thereby preventing undesired movements due to vibration and extraneous electrical impulses. This minimizes the chances of erratic indications which may confuse the pilot. In early instruments, electrolytic condensers of high capacitance were shunted across the movements operating the pointers to provide the necessary damping.

\section{LANDING BEAM}

The advantages of the landing beam, foreseen during its early development, are fully realized in its practical application at an airport. The landing path may be so directed that a landing aircraft following the glide path is automatically kept above obstructions without requiring exact knowledge by the pilot of the terrain over which he is passing. Secondly, the average landing path may be made to suit the particular airport merely by adjusting the power of the landing beam transmitter. Each individual aircraft may follow a path departing considerably from the average landing path and more closely suiting its flying characteristics simply by an adjustment of the sensitivity of the landing beam receiving set. The power adjustment at a given airport to secure a suitable average landing path and the sensitivity adjustment on each aircraft to depart by a desired amount from the average path, once made, are permanently fixed. A given aircraft then follows an optimum landing path at all airports equipped with landing beams. As a third advantage, the shape of the landing path is such that the aircraft maintains safe flying speed in following the landing path indications up to the point 



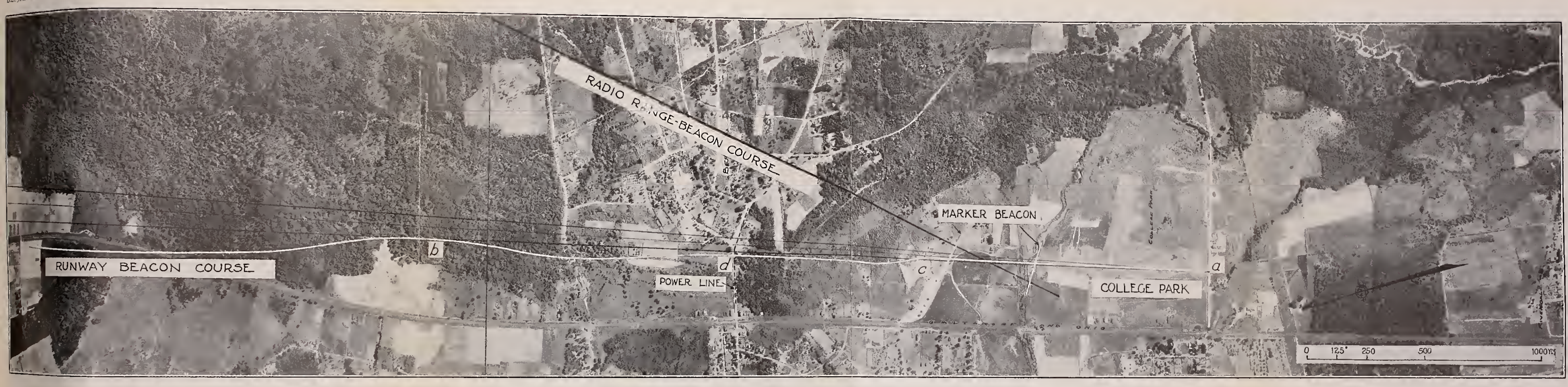
FIGURE 5.-Photographic strip of College Park, Mdd, airport showing effect of railroad tracks and power lines upon shape of runway beacon course. 

of receiving the boundary marker beacon signals. The aircraft engine is thus kept at safe operating speed during all maneuvers outside the airport boundaries. A fourth advantage is that the landing glide may be begun at any desired altitude within a rather wide range (say, 500 to 5,000 feet). Beginning the use of the landing beam does not, therefore, involve accurate location of any point at specific distance from the airport, but comes automatically so long as the pilot is following the runway beacon course in the correct direction and at an altitude within the prescribed limits. The fifth advantage

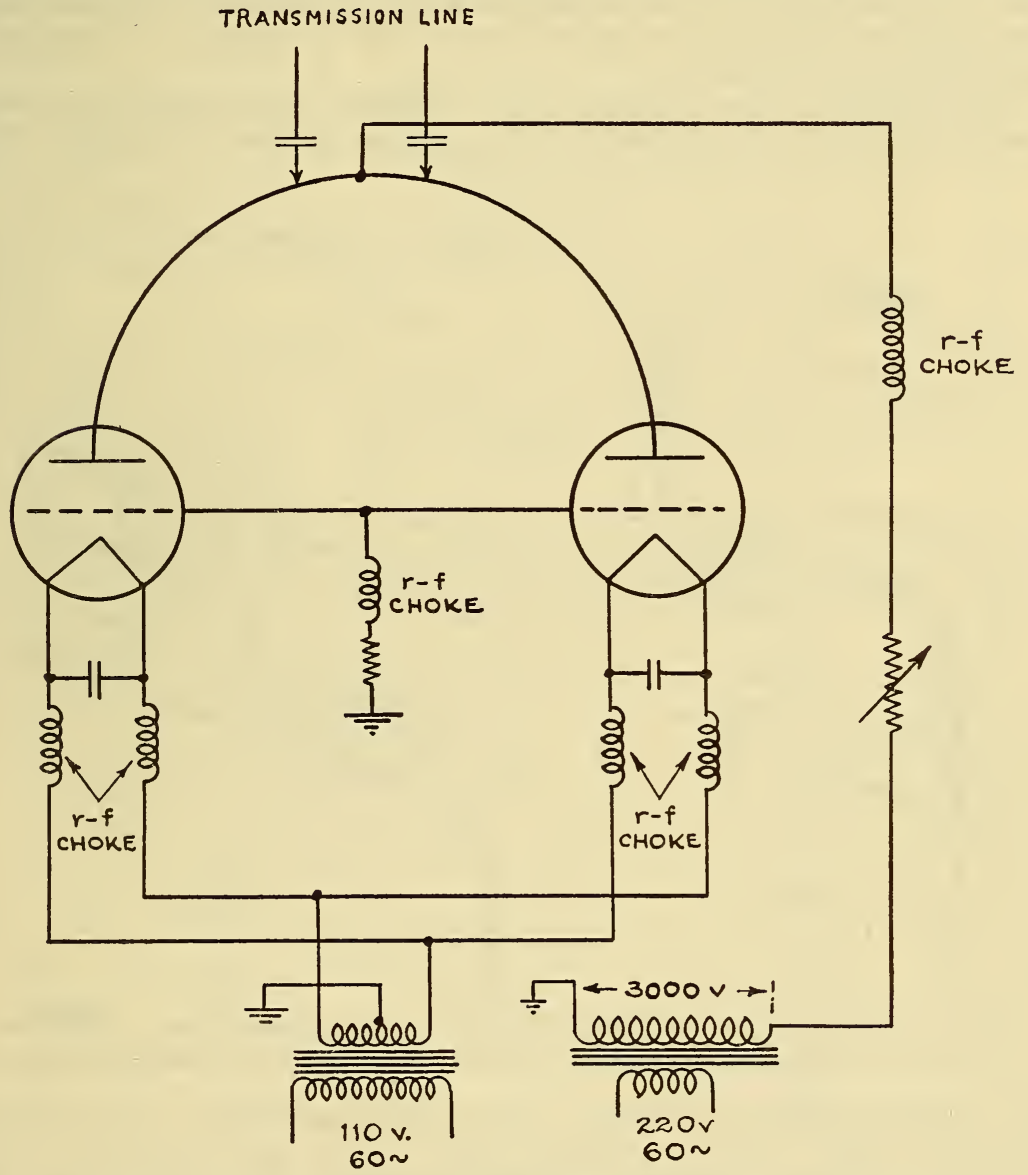

Figure 6.-Electrical circuit arrangement of landing beam oscillator.

lies in the ease of using the landing beam indications. No manipulation of equipment on the part of the pilot is required. The tuning is fixed. Since a line of constant field intensity is followed no control of volume is necessary. Other advantages will be evident from the following paragraphs.

The landing beam transmitting set may employ any transmitting circuit arrangement which can supply approximately 500 watts to the directive antenna array. Sixty-cycle modulation of the radio-

$8455-33-3$ 
frequency carrier is required for purposes of audio amplification and filtering in the landing-beam receiving set carried on the aircraft. The oscillatory circuit shown in figure 6, employing two 500-watt 3 -element tubes in push-pull, was used at College Park and at Newark. In recent experiments, substituting a quarter-wave transmission line for the filament chokes resulted in considerable increase in the efficiency of the oscillator.

The transmitter feeds power to the directive antenna array by means of a parallel-wire transmission line. A short-circuited or open-circuited loop at an experimentally determined distancé from the antenna end of the transmission line is utilized to eliminate radiation from the line.

The design of the antenna array depends considerably upon the horizontal angle over which landing beam service is desired. The
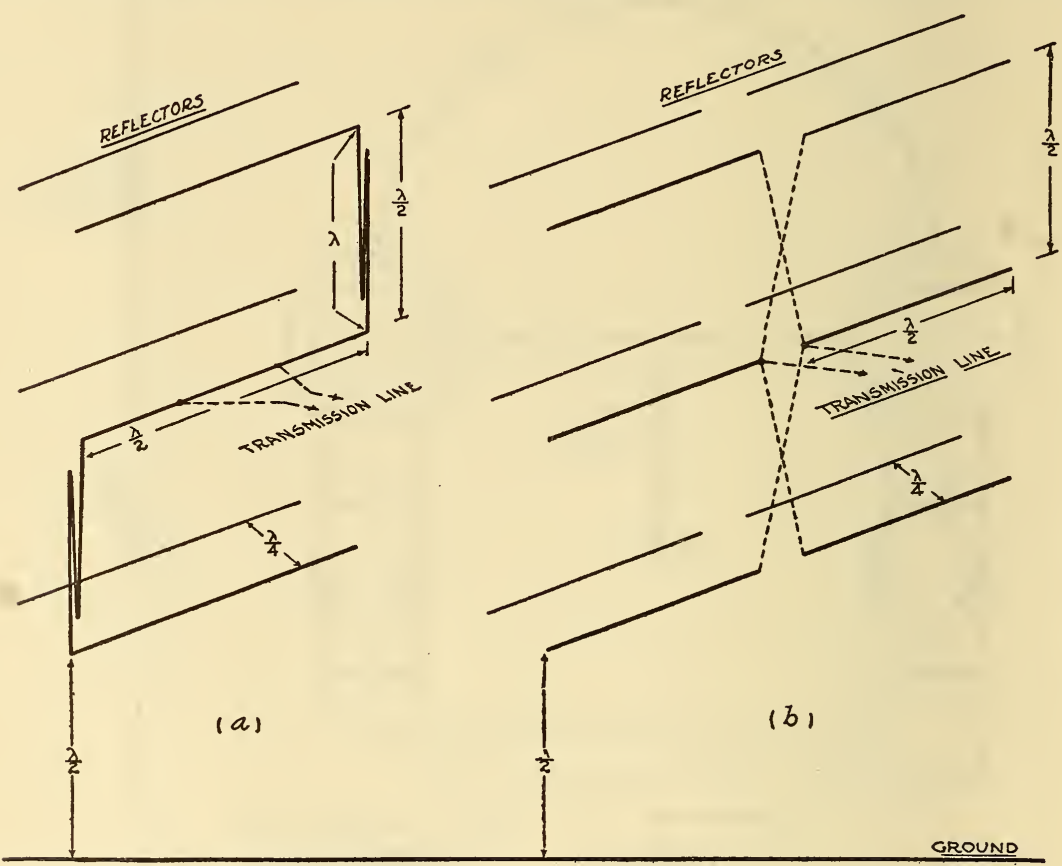

FIGURE 7.-Directive transmitting antenna arrays tested for landing beam use.

Yagi type of array, utilized in the early experiments, was given up because of the limited possible control of the space pattern in the horizontal plane. Where it is desired to provide service in all directions, a very simple antenna arrangement, suggested by the Deutsche Versuchsanstalt für Luftfahrt, may be used. This comprises simply a quarterwave vertical antenna, grounded at one end, placed in the center of the airport. The portion of the space pattern used is shaped like a bowl, suggesting the German name, "teller" antenna. With this arrangement, the landing beam transmitter may be placed in a pit in the center of the field. The practical difficulties consist firstly, of the objection to even a low antenna (2.7 feet for 3.3 meters wave length) placed in the center of an airport, and, secondly, the dependence upon the dielectric constant of the ground of the shape of the 
space pattern produced with vertically polarized waves. With horizontally polarized waves, such dependence is inappreciable, thereby insuring a fixed landing path under all weather conditions. The above considerations point to the use of a horizontal type antenna array located off the airport, with duplication of the transmitter and antenna array if more than one landing direction is to be served. However, as indicated in section III (1) it is not expected that many airports will require more than a 1-direction installation. In the few cases where such duplication is essential, the cost involved is not high, the landing beam transmitter and antenna array being extremely simple.

蜼. Two types of horizontal arrays shown in figure 7 (a) and (b) were tested at College

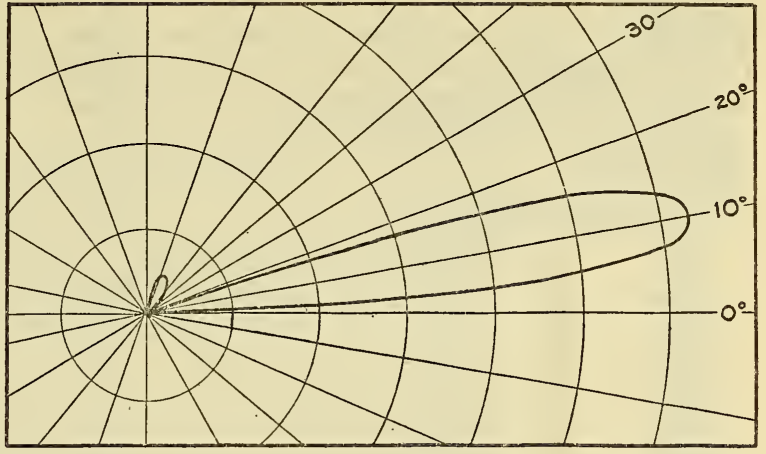

Figure 8.- Vertical directive characteristic of the landing beam corresponding to the trarsmitting antenna arrays shown in figure 7.

Park. In each case, the radiator was fed from the transmission line and the reflector, placed one-quarter wave length behind the radiator, was excited by induction from the radiator. Both antenna arrays gave essentially the same directive pattern in the vertical

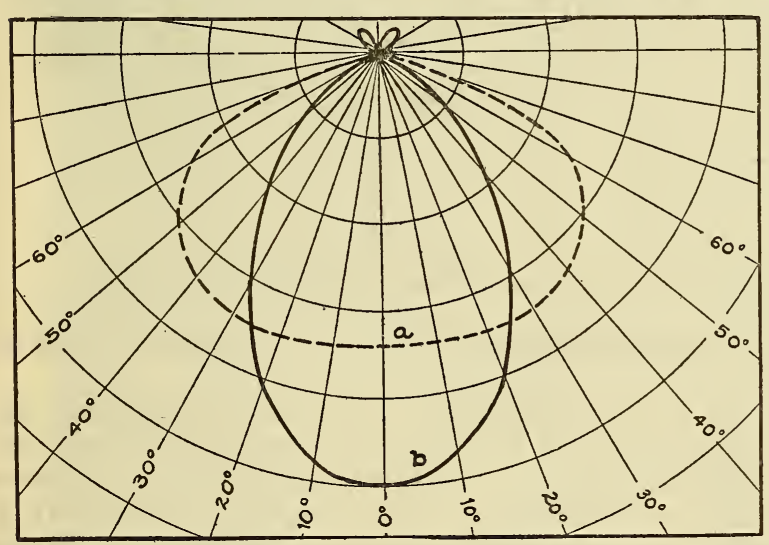

Figure 9.-Horizontal directive characteristics of the landing beam corresponding to the transmitting antenna arrays shown in figure 7. plane. (See fig. 8.) The directive pattern in the horizontal plane correponding to the array shown in figure 7 (a) is indicated in figure $9(a)$, and for the array shown in figure $7(b)$, by figure $9(b)$. Using the antenna array of figure $7(a)$ it is possible to provide landing beam service over a sector of approximately $110^{\circ}$, while with the antenna array of figure

$7(b)$ the useful sector is reduced to approximately $40^{\circ}$. At the limits of these sectors, the landing path for fixed receiving set sensitivity is about 10 percent higher than at the center. This difference is not important in practice. The choice between the two types of antenna arrays lies in consideration of the width of the sector in which service is desired and of the intensity of radiation in the area served for a given transmitter power. 
At the Newark airport (see fig. 3) the angle between the two hangar lines is approximately $40^{\circ}$. The antenna array chosen is accordingly that shown in figure $7(b)$. A photograph of this antenna array, as installed at the Newark airport, together with the transmission line feeding it, is given in figure 10. The short-circuited loop for impedance matching is also shown in this photograph. The transmitter and antenna array at Newark are located along side of the runway localizing beacon at the northeast end of the field, and the radiation directed in the southwest direction. Use of the landing beam is therefore possible only when coming in from the southwest quadrant. As indicated in connection with the discussion relative to location of

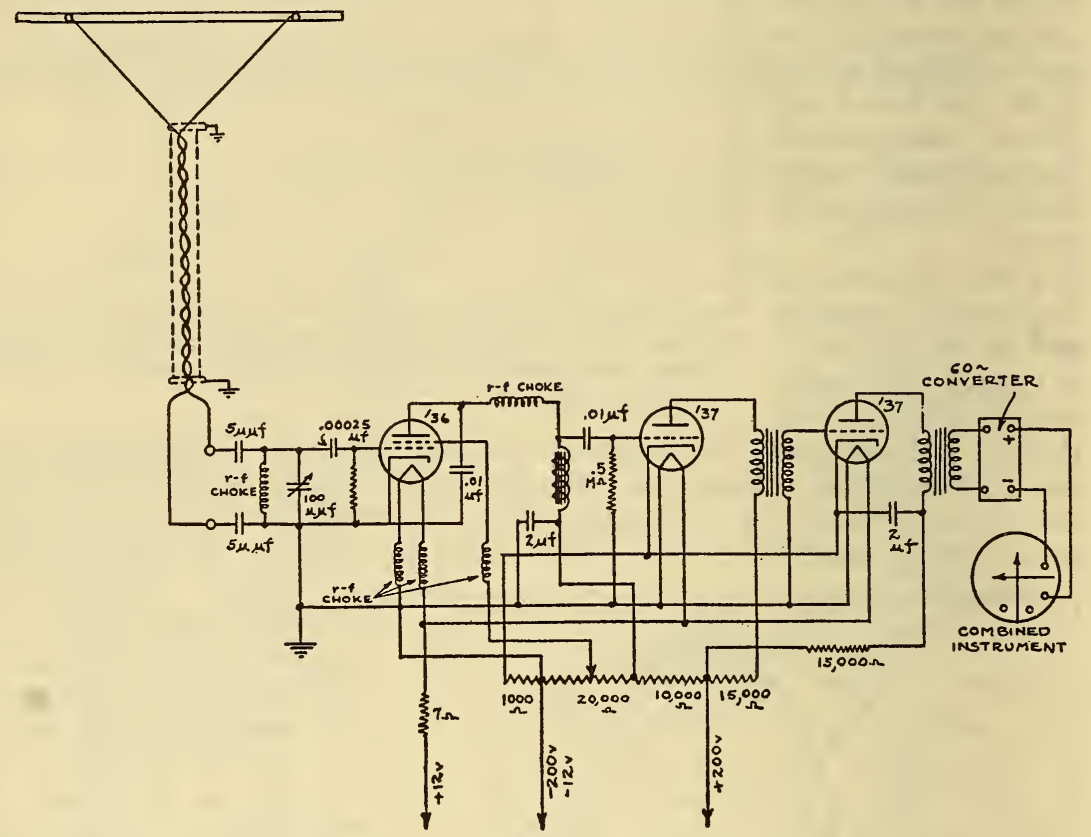

FIGURE 11.-Electrical circuit diagram of landing beam receiving set.

the runway localizing beacon, this is sufficient for all practical use of the system at Newark.

A circuit diagram of the receiving set used on the aircraft for receiving the landing beam signals is given in figure 11 and a photograph in figure 12. The receiving set comprises a detector and two stages of audiofrequency amplification. The detector is untuned, a simple high-pass filter being interposed between the detector input circuit and the transmission line feeding it in order to minimize interference from services operating on lower frequencies. The output from the receiving set passes through a mechanical filter, tuned to the modulation frequency at the transmitter (60 cycles) which provides further freedom from interfering signals. Adjustment of the sensitivity of the set is obtained by means of a variable condenser shunting the input to the detector grid. With this condenser the sensitivity of the set may be varied from 10,000 to 40,000 microvolts input for 6 milliwatts output. ${ }^{4}$ The sensitivity used in the tests at Newark

\footnotetext{
1 These figures are interpolated from measurements made at 10,000 kilocycles.
} 


\section{B.S. Journal of Research, RP602}

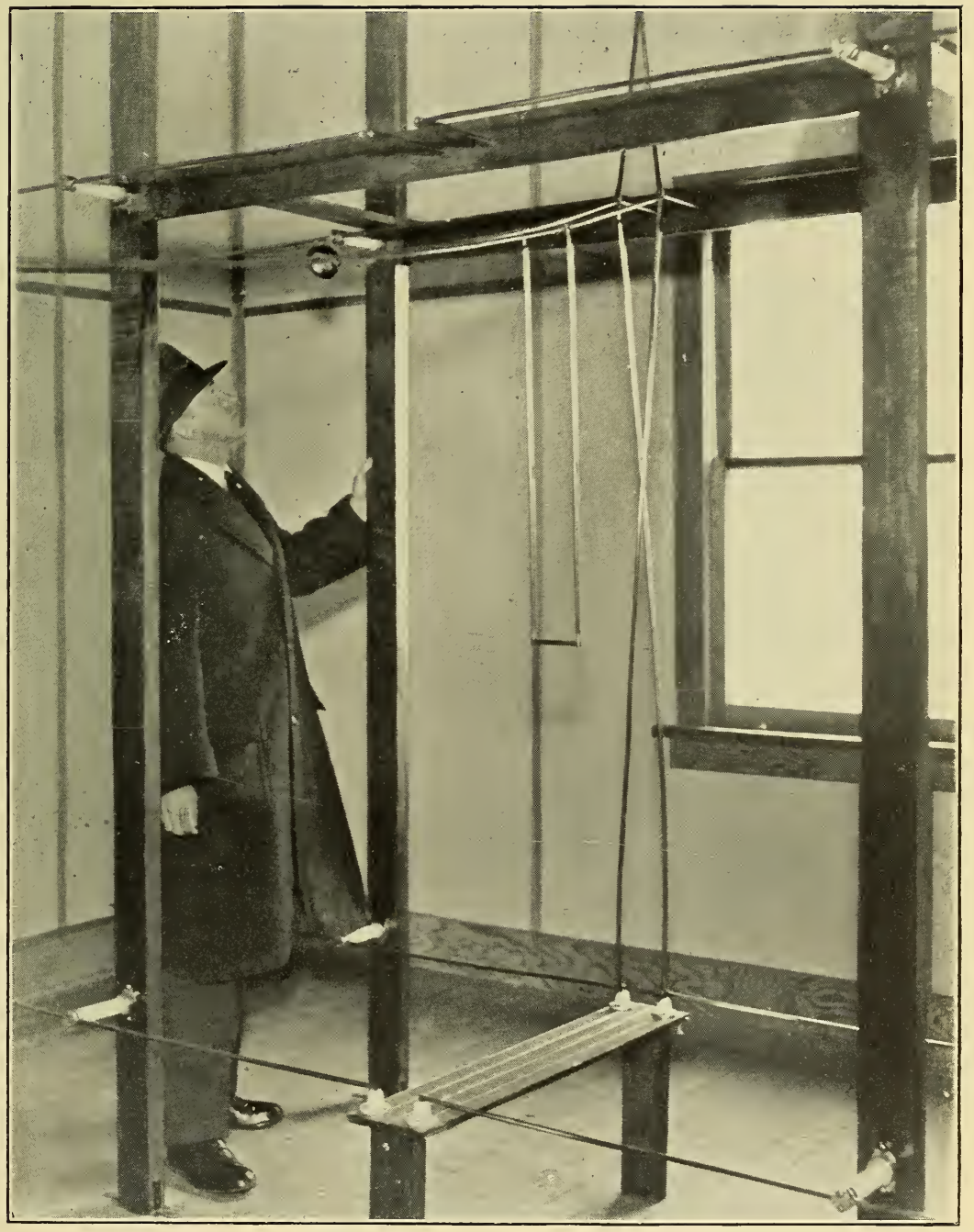

FIGURE 10.-Landing beam transmitting antenna array employed at the Newark Airport. 


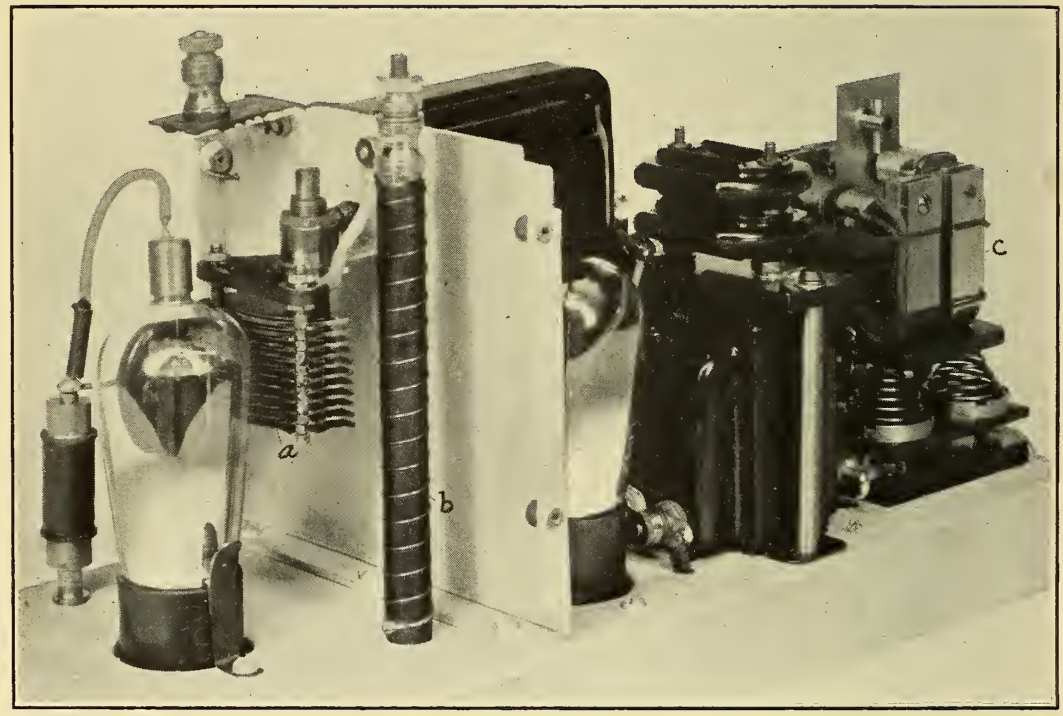

FIGURE 12.-Photograph showing inside view of landing beam receiving set.

$a$, Condenser for permanent adjustment of receiver sensitivity; $b$, portion of high-pass input filter; $c$, mechanical filter tuned to 60 cycles. 
and College Park was of the order of 20,000 microvolts. Because of the low receiver sensitivity, the simple means described above for securing freedom from interference have proved entirely satisfactory.

Special attention was given in the design of the receiving set to provide constant sensitivity for wide fluctuations in the supply voltages. Such design is required since the voltage of the storage battery, which serves as the central source of electrical power on the aircraft, may vary considerably even during a single flight. The means adopted are quite simple. Automobile-type receiving tubes are used which are especially designed to work on a wide range of filament voltages; a series resistor is used to step down the 12 volts from the storage battery to the required average value (6 volts). The high voltage supply, furnished by a dynamotor available in the aircraft for use with other receiving equipment, is impressed upon a voltage divider. Taps from the voltage divider provide the proper
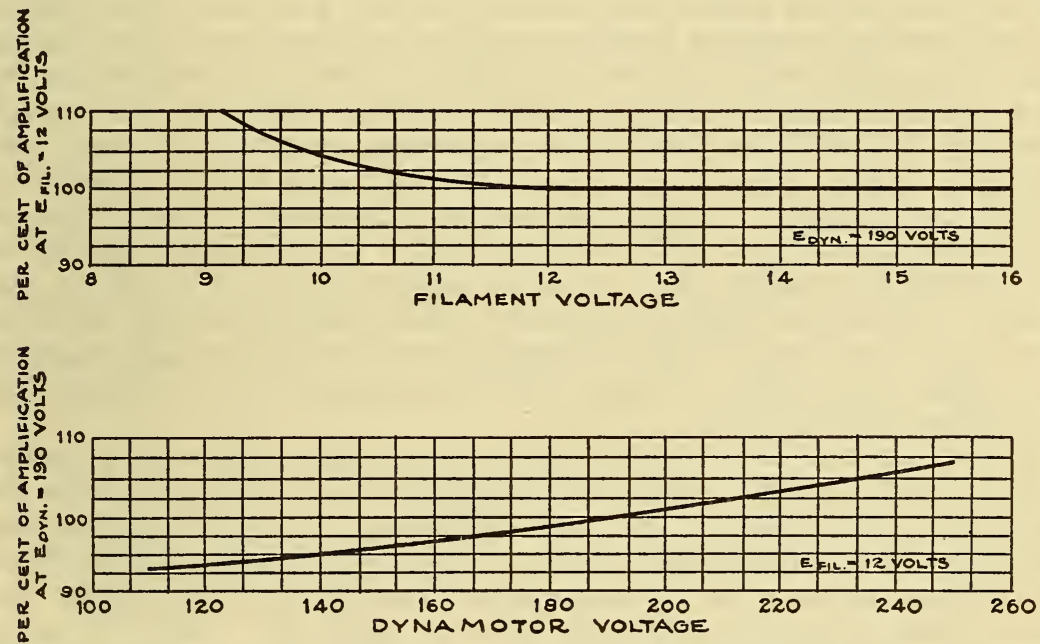

FIGURE 13.-Effect of variation of supply voltages upon sensitivity of landing beam receiving set.

voltages to the plate and shield grid of the detector tube and to the plates of the amplifying tubes. These voltages are fixed by test at values giving minimum change of amplification for large departures on either side of these values. Grid detection is used so that variations in the plate and shield grid voltages of the detector tube have minimum effects. Graphs showing the relation between the receiving set sensitivity and the supply voltages are given in figure 13.

The transmission line used for transferring voltage from the receiving antenna to the receiving set consists of a twisted pair of insulated wires inclosed in a metallic shield. Both ends of the shield are grounded to the airplane metallic structure and the transmission line run so that the shield is either insulated from contact with metal parts of the airplane or grounded thereto. The connection of the transmission line to the antenna is indicated in figure 11. The antenna consists of a horizontal copper rod of approximately one half wave length. A reflector is employed to reduce alteration of the space characteristics of the receiving antenna due to its proximity to the aircraft structure. Two locations for the receiving antenna were 
tried, one above the wing at the center, and the other ahead of the leading edge of the wing near the wing tip. In the first arrangement, the effect of reflection of the oncoming wave from the body of the airplane was to sharpen up the directivity of reception in the vertical plane, the direction of maximum reception corresponding to an angle above the wing surface. As a result, the deflection of the landing path indicator would increase considerably when the airplane was put into a dive and decrease during a climb. The use of a reflector placed above and somewhat behind the antenna compensated the effect of the airplane, reducing to considerable extent the vertical directivity of reception. However, the length and position of the reflector had to be determined by a long series of flight tests. In the second arrangement, the vertical receiving characteristic was found satisfactory. In the absence of the reflector, however, reflection of the oncoming wave from the leading edge of the wing caused a sharpening and distortion of the horizontal receiving pattern. Sharp horizontal directivity meant that an airplane coming down the landing path at an angle to the runway direction (in order to compensate for wind drift), would receive reduced landing indicator deflections. The use of a reflector behind the receiving antenna reduced these effects in marked degree by reducing the response of the antenna to signals from behind. The proper length of reflector corresponding to a given position ahead of the leading edge of the wing may readily be determined experimentally, since the adjustments are made on the ground. A horizontal pattern giving substantially constant received signal for departures of \pm 25 degrees from the head-on direction of the airplane, is readily obtained. This is satisfactory for all practical use of the landing beam.

Since the use of the landing beam is based upon following a line of constant field intensity below the inclined axis of the beam, it is essential that the power of the transmitter and the sensitivity of the receiving set, once adjusted, remain unchanged in order not to affect the landing path. The dependence of the landing path upon the transmitting set power output is shown in figure 14. Graph $A$ is for normal power output at Newark, approximately 350 watts. Graph $B$ corresponds to 10 percent increase while graph $C$ corresponds to 10 percent reduction in power output. These graphs were calculated from the expression given in equation (1) and derived by G. L. Davies of the Bureau of Standards. Experimental checks in an airplane gave excellent agreement with the calculated data. From a study of figure 14 it is evident that the change in the landing path is negligible even for a 10 percent change in power output. Such variation in power is hardly to be expected in practice.

$$
x^{2}=\frac{8 \pi A n I h}{\mathrm{E} \lambda} \mathrm{y}=p y
$$

where

$x=$ horizontal distance of airplane from landing beam transmitter

$y=$ height of airplane

$\mathrm{A}=$ numerical constant (depending upon field intensity due to single antenna)

$n=$ number of pairs of antennas and reflectors

$I=$ current in each antenna

$h=$ height of center of transmitting array above ground 
$E=$ field intensity necessary at receiving antenna to produce on-course indication

$\lambda=$ wave length

This holds provided $\frac{y}{x} ₹ 0.05$.

The change in landing path corresponding to \pm 10 percent change in amplification of the landing beam receiving set is about the same as that indicated in figure 14 for \pm 10 percent change in power. This is based on the use of square-law detection. A detector of a higher order than square-law would reduce the change in path from that indicated. The desire to minimize the possibility of such change led

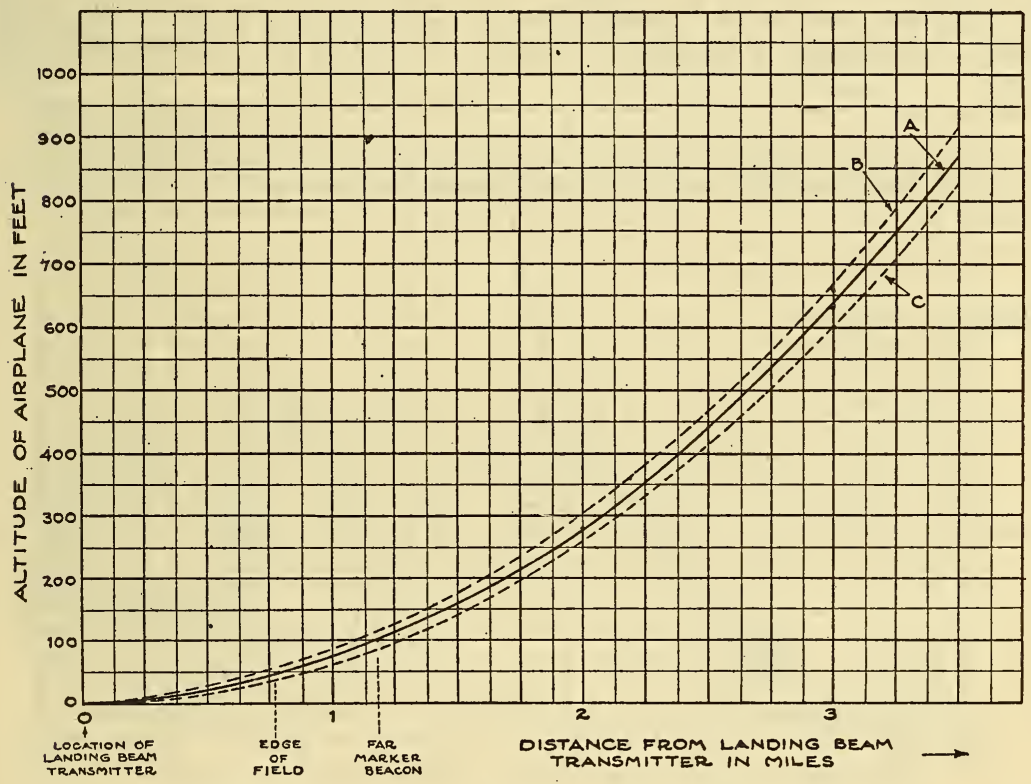

FIGURE 14.-Effect of changes in transmitting power upon landing path.

to the use of the simple type of landing beam receiver described. Since there is no tuning nor regeneration, and the sensitivity is not at all critical with variation in supply voltage, the only possibility for change in sensitivity is loss of emission in the receiving tubes. Repeated checks on the two test airplanes for a period of nearly a year showed such possibility to be rather remote. Routine service checks of the equipment at regular intervals are sufficient to eliminate any possibility of improper operation from this source. An effective overall check of the receiving equipment consists of applying a known voltage (of the landing beam frequency) to the landing beam receiving antenna and checking the reading of the landing path indicator. The voltage required to give "on-course" indication, as previously determined and recorded, is a good value to use for this test.

It is of interest at this point to indicate the adjustment procedure to be followed in installing the landing beam at a number of airports. For the purpose of explanation, assume that an installation has been made at one airport, say at Newark, and that it is desired to provide 
landing-beam service at a second airport of different characteristics, say at College Park. (The distance of the approach end of the field from the landing-beam transmitter is approximately 4,000 feet at Newark and 2,000 feet at College Park.) Assume furthermore that the receiving sets on a number of airplanes have been adjusted to give suitable landing paths at Newark and are to be used in landings at both airports. The problem is to adjust the power of the landingbeam transmitter at College Park to give satisfactory landing paths corresponding to the receiver sensitivities previously found desirable at Newark. The procedure is simply to calculate the required power to give a suitable average landing path (as determined from obstructions in the path, point of contact with the field, etc.), and to check this experimentally in an airplane. For the two test airplanes used in developing the radio landing system, the landing path at Newark is given by graph $A$ in figure 15 and the path at College Park by

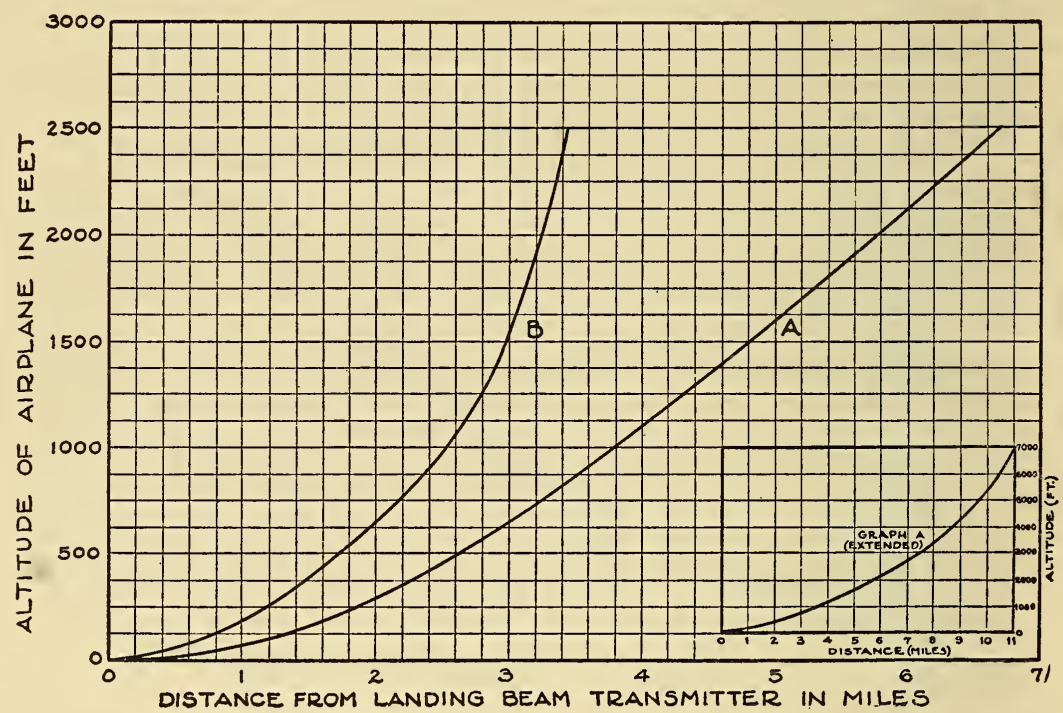

Figdre 15.-Landing paths used at Newark and at College Park.

graph $B$. The antenna power corresponding to graph $A$ is approximately 350 watts, and to graph $B$, approximately 175 watts.

Each of the landing paths shown in figure 15 really represents the path of the landing beam receiving antenna. The actual wheel height of a landing airplane is below this path by an amount depending upon the location of the receiving antenna. The difference is relatively unimportant except in determining the point of contact of the wheels with the ground. At Newark, the point of contact is 2,450 feet from the landing beam transmitter for an antenna height of 15 feet, 2,000 feet for an antenna height of 10 feet, and 1,400 feet for an antenna height of only 5 feet. If the antenna is to be considered mounted ahead of the leading edge of the wing, the first case corresponds to the average transport passenger airplane, the second to the average itinerant and mail airplane, and the third to the low-wing monoplane used in mail service. In the first two cases it is feasible to use the landing beam down to the point of contact with the ground. 
In the latter case, it is desirable to start settling down for a landing as soon as the boundary marker beacon signal is heard, in order that the airplane will not land too far downfield with the possibility of overrunning the field during taxying.

\section{MARKER BEACONS}

The function of the marker beacons in the radio landing system was outlined under section II. The transmitting set employed for the marker beacons is very simple, comprising a low-power radiofrequency oscillator, an audio-frequency oscillator providing grid modulation of the radio-frequency oscillator, and a rectifier to permit operation from the 60-cycle supply. The electrical circuit diagram for the marker beacon transmitting set is given in figure 16 . The transmitter is enclosed in a small weatherproofed box for protection from the elements and is completely shielded to prevent direct radiation.

The marker beacon transmitting antenna must meet several requirements. The radiated space pattern from this antenna must be

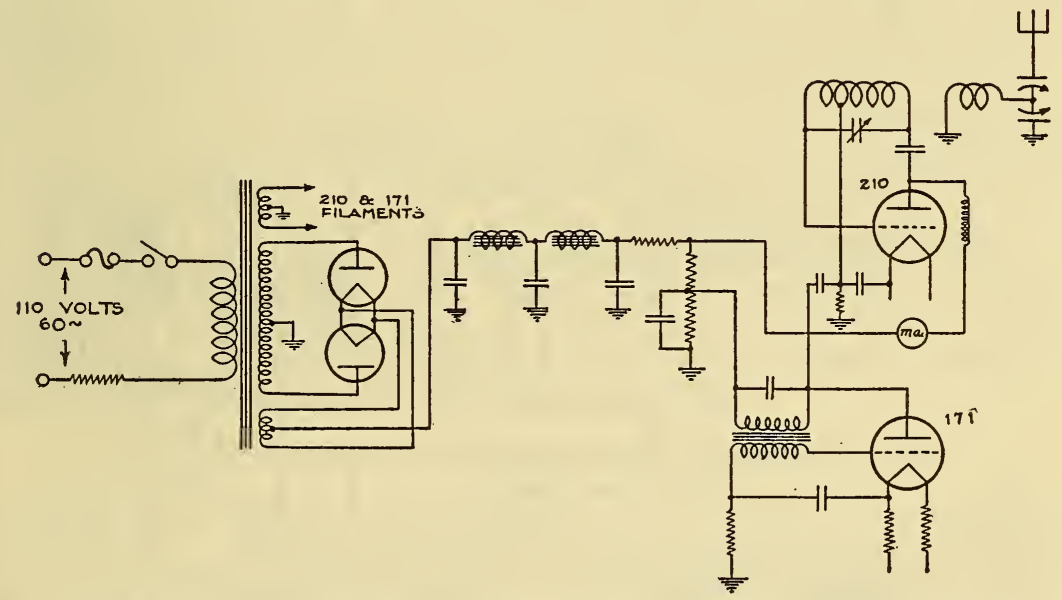

Figure 16.-Electrical circuit diagram of marker beacon transmitting set.

sharply directive upward forming what is virtually a wall of radio signals through which the aircraft passes. In addition, it must be possible to control the distance along the line of flight of the aircraft over which the signal is heard, thereby securing any desired sharpness of definition of a given boundary line. It must also be possible to provide marker beacon service for any desired distance along the boundary to be defined. The antenna adopted, a long horizontal wire, 2 to 6 feet high and stretched transversely along the line of flight of the aircraft, satisfies the above conditions. For a given receiving set sensitivity, sharpness of definition is controlled by the amount of power fed to the antenna. Service may be given over any length of the boundary line by increasing the length of the antenna. Thus at Newark, to provide service for any orientation of the runway beacon course within the $40^{\circ}$ sector, the field marker beacon antenna was made 2,500 feet long and the approach marker beacon antenna 3,500 feet long. Actually the antennas could have been made con- 
siderably shorter, since considerable radiation is had off the ends of this type of antenna which may be used as much as a quarter mile from the ends. To eliminate reflection from the ends and consequent setting up of nodes at intervals along the antennas, the antennas are terminated at each end into $600-\mathrm{ohm}$ resistors. Practically uniform service is had when passing over any point of the antennas.

The marker beacon transmitter and transmitting antenna arrangement provide great flexibility relative to the radio frequency on which

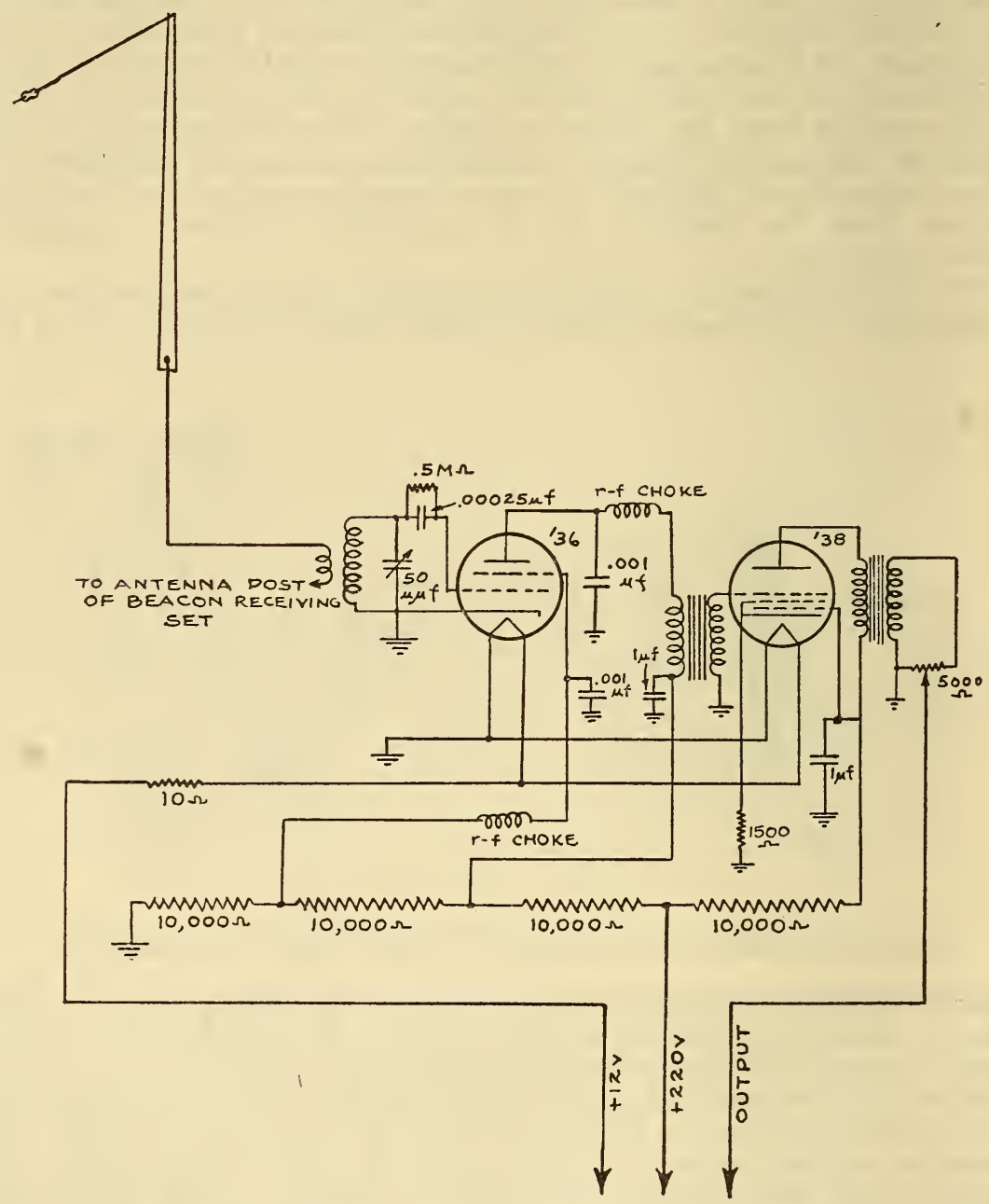

FIGURE 17.-Electrical circuit diagram of marker beacon receiving set for operation on 10,000 kilocycles.

they operate. The frequency may be anything from 200 to 20,000 kilocycles without imposing special features of design and is determined solely from considerations of the system as a whole. For application of the system as outlined in the foregoing description, the preferred frequency of operation is of the order of 10,000 kilocycles. A special 2-tube receiving set is then required on the airplane for receiving the marker beacon signals. A circuit diagram of a suitable 
receiving set is given in figure 17 . The set may be housed in the same chassis as the landing-beam receiving set and fed by the same power supply cable. The antenna coupling arrangement is such that the regular beacon receiving antenna also serves as the marker beacon antenna. The tuning and sensitivity of the marker beacon set once adjusted, require no further attention except for service checks in maintenance of the equipment.

In a series of tests at College Park the marker beacons were operated on the same radio frequency as the runway localizing beacon. The need for a special marker beacon receiving set was thereby obviated, the marker beacon signals being received on the regular beacon receiving set. Close control of the marker beacon power output was, however, required to prevent overloading of the beacon receiving set when the airplane was directly over the marker beacon antennas, since such overloading affected the accuracy of the runway beacon course indications. The tests demonstrated that this method of operation would not prove practicable in service.

A third scheme of operation was tried in the experiments at Newark. In this arrangement the marker beacons operate on the same radio frequency as the 2-way communication system $(3,105 \mathrm{kc})$, so that the marker beacon signals are received on the communication receiving set already available on the aircraft. With provision for automatic volume control operation of this receiving set, the arrangement is entirely feasible from a technical viewpoint. Its use will probably be continued for part of the experimental period of the service tests at Newark. This method is, however, not practicable for present service use of the landing system, since the transport lines using a given airport do not all employ the same radio frequencies for communication purposes. It becomes feasible only when there is available an airport transmitter operating on the marker beacon frequency and to be used for airport-control purposes only.

\section{MONITORING AND COMMUNICATION SYSTEM}

The landing system is well coordinated with the radio services already in use. The use of the airways radio range beacon for locating the vicinity of the airport has already been noted and will be amplified later on in this paper. The effective use of the 2-way communication system will be apparent from a description of the set-up used at Newark.

In addition to the ground equipment already described, there is installed at the Newark airport, in the National Guard Administration Building, a monitoring panel and a 2-way communication system. The monitoring panel comprises radio-receiving equipment tuned to the runway localizing beacon, marker beacons, and landing beam. Visual indicators show at a glance the status of operation of each transmitter. The 2-way communication system consists of a standard aircraft 50 -watt transmitter, operating on 3,105 kilocycles, and a suitable receiving set. With this equipment the operator may keep in constant communication with the pilot of a landing aircraft. Assurance can be given the pilot that the equipment is functioning properly (as seen from the monitoring panel), and that the airport is clear for a landing. While the control room in which this equipment is located overlooks the airport, nevertheless, under conditions of practically zero visibility, it has proved desirable to station a man 
at the southwest end of the field to assist in determining that the airport is clear. Remote-control junction boxes are accordingly located at this end of the field, which provide direct 2-way communication with the landing aircraft as well as interphone communication with the control room. The junction boxes and the control cable from the National Guard building are shown in figure 3.

While in the Newark installation the communication service was on the same radio frequency as the marker beacons, the service is in no way affected if the marker beacons are modified to operate on 10,000 kilocycles.

\section{COORDINATION OF RECEIVING AND INDICATING EQUIPMENT}

Considerable study was given during the tests of the landing system to the problem of minimizing the number of radio controls to be operated by the pilot. In addition to the regular tuning and volume controls already provided on the aircraft for use with the beacon and communication receiving sets, but three switches are required. One of these is the volume-control switch which selects either manual or automatic volume-control operation of the beacon receiving set. The second is the reversing switch for the vertical pointer of the combined instrument, provided so that the deflection of the pointer and the direction of deviation of the aircraft with respect to the course may correspond whether the aircraft is flying away from or toward the runway beacon. The third switch is the "flight-land" switch. In the "flight" position this switch connects the horizontal pointer movement of the combined instrument to the output of the reed converter so as to indicate the volume of received signal in the output of the beacon receiving set. This indication is for the purpose of informing the pilot that his receiving set and the beacon transmitter are functioning properly. Otherwise the vertical pointer, which indicates the beacon course, being of the zero-center type, might read "on-course" with the beacon signal off or the receiving set not functioning. In the "land" position this switch turns on the landing beam and marker beacon receiving sets and connects the horizontal pointer of the combined instrument to function as the landing path indicator, as described in the foregoing.

It is interesting to note that with the "land-flight" switch in the "flight" position, all of the equipment in operation-i.e., the beacon receiving set, the reed converter, the combined instrument, the volume-control switch, and the course-reversing switch-are useful in receiving indications from available visual type airways radio range beacons. The equipment added for landing purposes comprises merely the combined landing beam and marker beacon receiving set.

The coordination of the radio instruments with the flight instruments to provide most convenient use by the pilot constituted an important problem. Typical instrument panel arrangements are shown in figures $18(a)$ and $(b)$. Figure $18(a)$ is for the panel in the airplane used for the "hooded" landings, while figure $18(b)$ is for the panel in the cabin airplane used for demonstration purposes. The layout in figure 18 (a) is based on the principle of having, as nearly as possible, all the direction indicating instruments in a vertical row, and all the instruments giving attitude of the airplane in a horizontal row. In accordance with this arrangement the combined instrument (because of its vertical pointer), is placed in a 
B.S. Journal of Rescarch, RP602
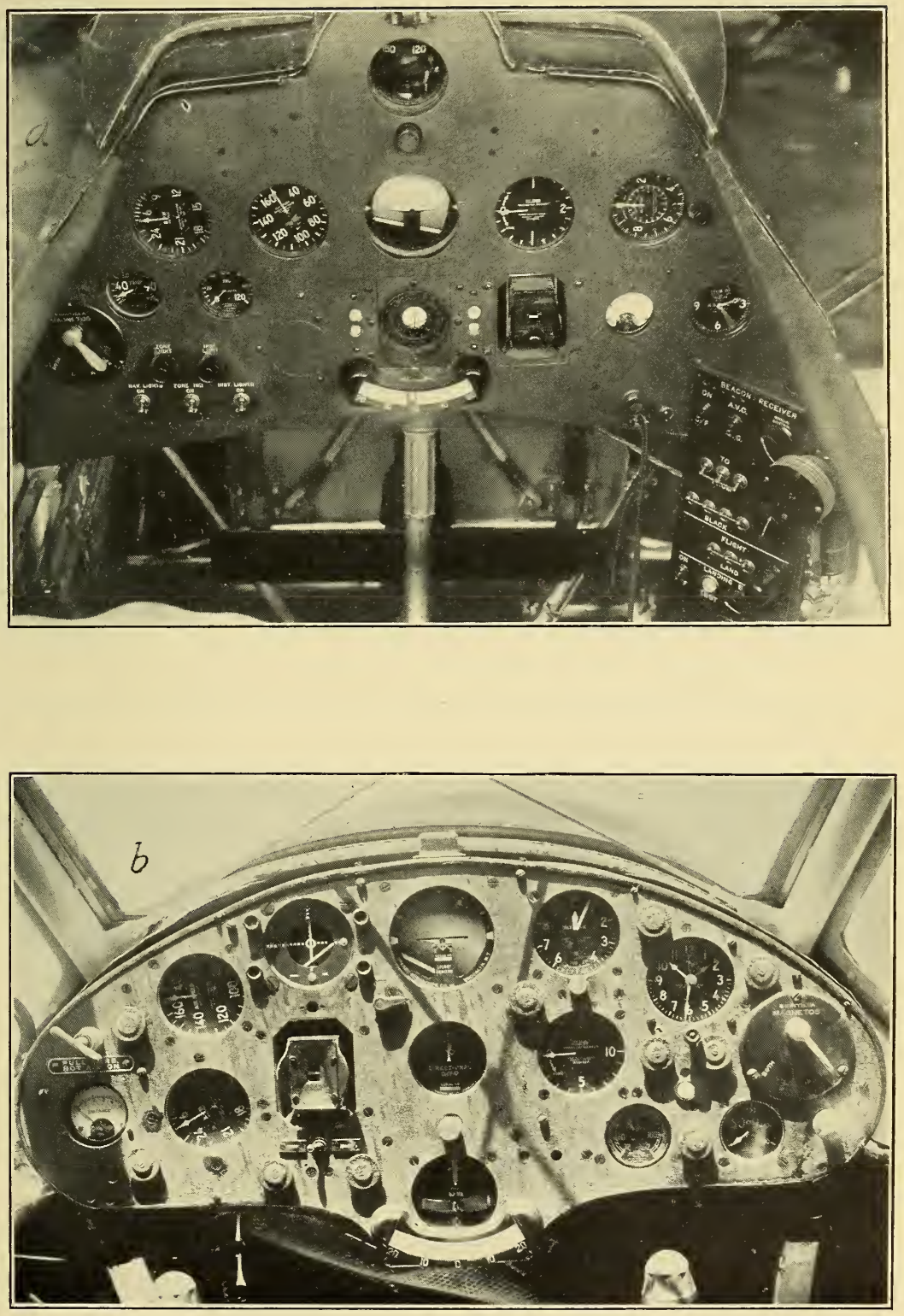

Figure 18.-Typical arrangements of airplane and radio instruments on pilot's instrument panel. 

vertical row with the gyroscopic compass at the top, and the magnetic compass ${ }^{5}$ at the bottom-hidden by the control stick. The horizontal row contains, from left to right: The tachometer, the air-speed indicator, the gyroscopic artificial horizon, the rate of climb indicator, and the barometric altimeter. These instruments are mounted so that during normal flight all the pointers are in the horizontal position. Departure of any pointer from this position immediately draws the pilot's attention to the particular instrument giving the off indication. To the right of the combined instrument is seen a reed indicator, and to the right of that, the distance indicator. The location of these instruments is of no particular importance. The reed indicator gives the same indication as the vertical pointer of the combined instrument and was used by the pilots for check purposes only; it is not expected that this instrument will be required in service installations. The distance indicator, being used only occasionally during a flight, may be mounted in any convenient location. Because of limited space, no turn indicator is provided on this instrument panel, the gyroscopic compass serving for this use.

In figure $18(b)$, the instrument layout is quite different. The idea of placing all the attitude-indicating instruments in a horizontal row is departed from in order that the important instruments may be mounted as close to each other as possible. The need for travel of the pilot's eyes over the instrument panel is thereby reduced. The grouping provides better correlation of the vertical pointer of the combined instrument with the gyroscopic compass, and of the horizontal pointer with the attitude-indicating instruments. The magnetic compass is not shown in this view. It is of in terest to note at this point, that different pilots have different preferences for the instrument arrangement on the panel. Nevertheless, the proper grouping of instruments was found to be of utmost importance to the success of the tests on the landing system. It was found, for example, that the demonstration airplane was much easier to fly on the landing system than the airplane used in the hooded tests. "This was because of the improved instrument grouping and also because the instrument panel on the demonstration airplane is at a greater distance from the pilot than in the case of the "hooded" airplane, so that more of the instruments are focussed in the pilot's view, thereby providing easier coordination.

\section{OPERATION OF THE SYSTEM}

The operation of the radio-landing system may best be explained by outlining several typical examples of its use.

\section{METHOD OF MAKING A LANDING DURING FOG}

Major use of the system will probably consist of facilitating safe landings during fog conditions. The term "zero ceiling, zero visibility" usually applies to a ceiling height of from 50 to 100 feet and a visibility of from one eighth to one quarter mile. Under these conditions, use of the system is extremely simple, as may be shown by an account of an actual blind flight from College Park, Md., to the Newark Airport, during which radio was the sole means used for navigation. The flight was made on March 20, 1933, as a practical

5 The magnetic compass is needed only for setting the gyroscopic compass to correct for precession. 
demonstration of the landing system. The flight crew consisted of J. L. Kinney, pilot, W. W. La Violette, mechanician, and the writer. The ceiling was so low, upon starting from College Park, that it was found impossible to fly below it. Pilot Kinney therefore maneuvered the aircraft to an altitude of 3,000 feet and maintained this average altitude throughout the rest of the flight. At this altitude no sight of the ground or sky was had except for an instant over Baltimore. The fog was like a milky blanket surrounding the aircraft. Guidance from College Park to Hadley Field, New Brunswick, N.J., was obtained through the use of the Washington and Hadley Field oural type radio range beacons. After passing through the "zero-signal" zone of the Hadley station, the beacon-receiving set was tuned to the frequency of the runway beacon at the Newark Airport $(278 \mathrm{kc})$. The vertical pointer of the combined instrument showed approximately "on-course", the projection of the northeast-southwest runway at Newark being approximately over the Hadley station. The distance indicator was off-scale, showing that the airplane was more than 5 miles distant from the runway-beacon transmitter. The "flight-land" switch was thrown to "land", thereby turning on the landing beam receiving set and connecting the horizontal pointer of the combined instrument for operation from the output of this set.

Flying at 3,000 feet altitude, the horizontal pointer of the combined instrument began to deflect, gradually reaching the horizontal "oncourse" position. This corresponded to a distance of 8 miles from the landing-beam transmitter, as determined from the normal landing path at Newark. (See fig. 15, graph $A$.) After communicating with the 2 -way communication station at the airport to determine that the field was clear for a landing, the pilot maneuvered the airplane to keep the two pointers intersecting over the small circle in the center of the combined instrument dial. This gradually brought the aircraft along the runway direction and down the landing path shown in figure 15. (See also fig. 3.) Since the wind was from the northeast quadrant and of about 6 miles velocity, no particular effort was required for staying on both courses. The distance indicator showed continuous approach to the airport boundary, and the barometric altimeter (while not sufficiently accurate for landing) showed continuous approach of the aircraft to ground. When within about 2,000 feet from the southwest edge of the airport, the high-pitched marker beacon signal began to be heard becoming most intense at 1,700 feet from the edge and receding beyond that point. At this stage of the landing the ground became visible for the first time, the aircraft being somewhat over 100 feet above the ground. The pilot proceeded to land visually. Had the ground not become visible, the pilot would have continued at the same engine speed until the lowpitched field marker beacon signal was heard. He would then throttle down the engine and pull back the control stick so as to be in correct position for a 3-point landing when contacting the ground.

Several modifications of the above procedure for landing might arise, particularly at the start of the landing maneuvers, depending upon the location of the airways radio range beacon with respect to the airport and also upon the direction of flight. For example, in the case of a flight from Hartford, Conn., to Newark, N.J., the northeast course of the Hadley Field radio range beacon would be followed. Since this course passes within a few miles of the Newark airport, the 
pilot would not proceed as far as the "zero-signal" zone over the Hadley Field station, but would tune to the frequency of the runway localizing beacon at Newark, at intervals during the estimated last 30 miles of the flight, until signals from the runway beacon were received. He would then employ the course indications from this beacon in the standard way for locating the airport and orienting the aircraft along the desired landing direction. Again, consider a case where the airways radio range beacon is located, say, northwest of an airport and a pilot coming in from the northwest direction wishes to land due west along the east-west runway. Upon reaching the "zero-signal" zone over the radio range-beacon station, the pilot would tune his set to the frequency of the runway beacon. Knowing the geography of the field, he would circle the runway beacon at fixed radius (as determined from the distance indicator) and would count the number of courses passed through. In this case, the third course would be the one he would follow in order to secure the desired landing direction.

Other departures from the landing procedure outlined occur when the wind direction is not from the quadrant for which landing service is provided. Referring to the Newark airport installation shown in figure 3, assume that the ceiling is 100 to 200 feet with a northwest wind of 15 to 30 miles per hour velocity. In following the spatial landing path, the pilot must now "crab" into the wind in order not to drift east of the runway course. The exact angle of "crab" is determined by trial and error as indicated in section III (1). Upon breaking through the ceiling, the pilot maneuvers the aircraft below the ceiling in order to land into the wind. A very interesting example of such a landing was experienced during demonstrations of the system at Newark on April 6,1933. Rain and sleet conditions were prevailing with a ceiling of somewhat over 100 feet. When at about 5 miles southwest of the airport, the wind was from the southwest being quite gusty and attaining a velocity of possibly 40 miles per hour. At approximately 3 miles from the airport a wind-shift line was encountered, the wind direction changing suddenly to northwest. In spite of the gustiness, and the sudden change from a strong tail wind to a strong cross wind, the pilot was able to follow accurately the indications on the combined instrument. Upon coming within sight of the ground (at 100 feet), he circled the field at this altitude and landed into the wind.

Consider another case, where the ceiling is 50 feet or less and the wind from the northwest direction, of 10 to 15 miles per hour velocity. In following the runway beacon course, the pilot determines the angle of "crab" to compensate for wind drift and maintains the proper compass bearing to effect proper wind-drift correction. This compass bearing is followed until after hearing the signals from the approach marker beacon. As soon as the field marker beacon is heard, and assuming that the ground is then not in sight, the pilot swings the airplane to assume the true compass bearing of the runway, thereby preventing running off the runway after landing. It is interesting to note that while fog conditions corresponding to this case were not encountered during the tests at Newark, many of the hooded landings to be described in the following were made with cross winds of from 10 to 20 miles. The simulated visibility for these tests was, of course, absolute zero. 


\section{USE OF SYSTEM IN EVENT OF FAILURE OF ONE OF ITS ELEMENTS}

A remarkable feature of the radio landing system is that it is possible to shut off any one of its three elements and still furnish enough information to permit an emergency landing.

Assume first that the two marker beacons are not operating. Warning of close approach to the airport is then given by the indications of the sensitive barometric altimeter (corrected for barometric pressure and for the altitude of the airport). The pilot following the landing beam indications notes that the altimeter shows closer and closer proximity to the ground. Obviously, he must be approaching the airport. This information permits him to reduce his landing speed so that contact with the ground will not occur at too high a speed.

Next assume that the landing beam is shut off. In this case, one end of the field is defined by the marker beacons and the opposite end by the "zero-signal" zone over the runway beacon. The runway direction is, of course, also defined. The procedure for landing consists in finding the "zero-signal" zone over the runway beacon, then following out the runway course in the direction of the marker beacons at, say, an altitude of 1,000 feet. The time taken to reach the marker beacons is then a measure of the ground speed of the airplane. Maintaining the same altitude and the same engine speed, the pilot continues to follow the runway course in the same direction until he computes his position to be, say, 3 miles from the airport. The distance indicator serves as a check on this computation. The pilot then makes a $180^{\circ}$ turn and reduces his engine speed to start a glide which, if begun 3 miles from the airport at 1,000 feet altitude, is calculated to land the airplane somewhere near the center of the field. The runway-course indications serve to check wind drift, while the marker-beacon signals operating in conjunction with the sensitive barometric altimeter substitute for the landing beam in giving a measure of the height of the airplane as it crosses the airport boundary.

Finally, assume that the runway localizing beacon is not operating. In this case, the desired landing runway direction is approximately located from a knowledge of the orientation of the runway with respect to the main radio range-beacon station and by use of the compass. Advantage is taken of the directional properties of the landing beam receiving antenna to secure more definite orientation along the true landing direction. As noted under section III (2), the received landing beam signal measured on the horizontal pointer of the combined instrument is a maximum when the nose of the airplane is pointed at the landing beam transmitter and decreases for angular departures of the airplane on either side of this heading. The effect is purposely broadened to provide minimum reduction for $\pm 25^{\circ}$ change in heading of the aircraft, in order that the pilot does not lose the landing beam indications when "crabbing" due to cross winds. However, close observation permits noticing the effect for deviations of $\pm 5^{\circ}$. The landing-beam receiver may therefore also be used as a direction finder and, in conjunction with the compass, is capable of determining the true runway direction.

Each of the above three problems were actually worked out in flight tests in a hooded airplane. The possibility of effecting a safe 
landing in spite of the failure of any one of the three elements of the system has added materially to the confidence of the test pilots in the practicability of the system.

\section{SIMPLIFICATION OF SYSTEM FOR ECONOMY PURPOSE}

The foregoing discussion suggests that it may prove feasible to reduce the number of elements of the landing system with a view to reduction in cost. This procedure is not considered desirable. The indications given by the combination of the three elements are so definite and instinctive that breaking up the combination is not to be considered except in emergency cases.

One avenue of economy lies in simplification of the runway localizing beacon, the cost of which is estimated as approximately 50 to 60 percent of the cost of the complete ground installation. One arrangement suggested is to use an aural type runway beacon. Some saving is then obtained in the transmitting equipment and, in addition, the need for the reed converter and combined instrument at the receiving end is obviated. The vertical pointer of the combined instrument is then not required and a simple direct-current micro-ammeter may be used for the landing path indications. The lack of sharpness of the aural runway course indications, the need for manual control of sensitivity of the beacon receiving set as the airplane approaches the transmitter, and the lack of automatic coordination of the landing path and runway course indications, are disadvantages of this arrangement.

A second and preferable arrangement results in material cost reduction without at the same time affecting the service rendered. This consists of so locating the airways radio range beacon that one of its courses coincides with the major landing direction of the airport. Where feasible, the entire cost of the runway beacon is eliminated. If the airways radio range beacon is of the visual type, the service is in no way altered. This arrangement was tested at Newark, using a course oriented along the Newark runway from the simultaneous phone and beacon located at Elizabeth, N.J., and was found entirely practicable. The beacon service given by the Elizabeth station is of the combined visual and aural type described in the June 1, 1933, issue of the Air Commerce Bulletin.

\section{PERFORMANCE DATA AND TESTS}

\section{TESTS AT COLLEGE PARK, MD.}

The experimental installation at the Newark airport was preceded by exhaustive tests at College Park, Md., where the practicability of the system was studied by means of flights and landings in an airplane equipped with a canvas hood over the pilot's cockpit (rear cockpit of airplane in fig. 6). The first completely blind landing was made by Pilot M. S. Boggs on September 5, 1931. Over a hundred hooded landings were subsequently made by Mr. Boggs. A check pilot was used in the front cockpit to take care of faulty landings or other emergencies. The remarkable accuracy of the system was well established by these hooded landings. The landing runway at College Park is only 2,000 feet long and 100 feet wide with the approach

$8455-33--4$ 
unobstructed for a lateral distance of only 300 feet. Off the runway, the landing field is quite rough. In consequence, the runway beacon course had to be made sufficiently sharp to give appreciable off-course indications on the aircraft for deviations of the order of 20 feet (at the approach end of the field). At a distance of 5 miles from the transmitter, a deviation of only 250 feet from the runway course could be detected. The actual shape of the runway course is given in figure 5 . Tests over an extended period of time showed the course to be fixed in space regardless of weather conditions.

Obstructions in the approach at College Park also necessitated close control of the landing path. To secure a suitable landing path it was necessary for the airplane to clear a house chimney located approximately 1,500 feet from the edge of the field by about 8 feet. The necessary fixed landing path was obtained by maintaining approximately constant power output at the landing beam transmitter and through the use of the landing beam receiving set described in section III (2). It is interesting to note that from the beginning of use of this receiving set, no adjustments of receiver sensitivity were required over a period of nearly a year, and that but two receiving-tube replacements were made during this period.

Theoretical consideration shows that the landing path indications should increase in sharpness as the aircraft approaches the ground. This was clearly shown in figure 30 of the paper of reference 1. Test data taken at College Park corroborate this conclusion. Departures from the landing path of \pm 5 feet could be readily detected when the aircraft was over the edge of the field (at 30 feet altitude) while deviations of \pm 50 feet were apparent at a distance of 3 miles from the airport (1,600 feet altitude).

An extended study was made of the possible effect of varying ground conditions due to changes in weather upon the shape of the landing path. The path was found to remain exactly the same under all weather conditions with one exception. After a heavy snowstorm in February 1933 the ground was covered with about 8 inches of dry snow having, a hard surface crust. The landing path was then found to be raised as follows from the true path indicated by graph B of figure 15. At 3 miles distant from the landing beam transmitter, the new altitude was 2,000 feet instead of 1,600 feet; at 2 miles, it was 800 feet instead of 650 feet; at 1 mile, it was 205 feet instead of 175 feet; while at the approach end of the field, it became 35 feet instead of 30 feet. The landing path could still be followed down to a landing, although steeper than usual. Flight tests during the following few days showed that the path gradually returned to its normal shape as the snow melted, reaching this normal shape as soon as the snow crust was dissolved and before spots of ground could be seen through the snow. In other snowstorms, the raising of the landing path did not occur, probably because of the absence of the peculiar reflecting conditions from the snow crust obtaining in this particular instance.

\section{DEMONSTRATIONS AND TESTS AT NEWARK, N.J.}

Upon completion of the tests at College Park, it was decided to make an installation at Newark to determine the operation of the system under the conditions obtaining at a busy commercial airport. Other objects of the installation were to focus attention on the prac- 
ticability of the landing system, to cooperate with manufacturers in making the equipment commercially available and to cooperate with air transport operators in experimental use of the system.

The tests and demonstrations at Newark began in February 1933 and have continued to date. Two test airplanes were used, one being equipped with two cockpits for hooded landings and the second, a cabin airplane for demonstration purposes. Besides making a large number of hooded landings, it was possible to fly at all times when the scheduled air mail and passenger airplanes were on the ground because of fog. The operation of the system was demonstrated in the air to many engineers and officials as well as to nearly 100 air-transport pilots. It is interesting to note that not even a minor adjustment of the transmitting equipment nor of the receiving equipment on the two test airplanes was required (other than ordinary maintenance), during the entire period of the tests to date.

A few of the more important tests and demonstrations are summarized herewith.

March 1: Pilot Kinney made three excellent hooded landings. Prevailing high cross winds had limited total previous practice under the hood to 3 hours.

March 2: Flight demonstrations of the system were made with leading press representatives as passengers during a snowstorm with strong cross winds and a ceiling of about 200 feet.

March 7: Pilot Kinney made 12 excellent consecutive hooded landings.

March 14: Numerous demonstration flight tests were made under conditions of very low visibility, 100 to 200 feet ceiling. Engineers and officials who were given the flight demonstrations lost some of the nicety of operation of the system since they could not see their position relative to the ground except during the latter portions of the landings.

March 15: Pilot Kinney made three solo take-offs and landings under conditions of very low ceiling and visibility (approximately 50 -foot ceiling and one eighth mile visibility). All other flying to or from the airport was interrupted at this time.

March 20: Completely blind flight made from College Park, Md., to the Newark Airport. Details of this flight are in section IV (1).

March 31: Pilot Kinney made several demonstration hooded take-offs and landings in the presence of moving-picture news-reel photographers and representatives of the press. Col. Clarence M. Young served as check pilot.

April 3, a.m.: A representative of the press with some flying ability was taken up as check pilot and Pilot Kinney made a hooded take-off and landing.

April 3,p.m.: After a thorough inspection of the ground equipment and a preliminary flight in the cabin airplane, Col. Charles A. Lindberg made two hooded landings with but slight assistance from Mr. Kinney, serving as check pilot.

April 4 to 6: Heavy fog conditions occurred on each morning of these dates, which interrupted all flying to or from the Newark Airport. Pilot Kinney made a large number of solo take-offs and landings each morning. On two occasions the fog extended only up to about 2,000 feet altitude, above which the sun could be seen. Still, several transport airplanes had to wait on the ground at airports 
within 100 to 200 miles from Newark until they were assured that the fog had dissipated.

April 6: A demonstration of the system was given in the cabin airplane during driving rain and sleet and low visibility. The runway beacon and landing beam course indications were accurately followed even though a wind shift line was encountered during the flight. Details of this flight are given in section IV (1).

The system has proved inherently simple to use by pilots. Experience indicates that a good pilot, already experienced in instrument flying, becomes thoroughly acquainted with the use of the landing system after about 5 hours' hood practice. He is then capable of making consistent hooded landings which approach very nearly the type of landings he would make during good visibility.

The success of the tests and demonstrations has aroused considerable interest on the part of air line pilots, air transport operators, radio and aircraft manufacturers, and air officials of a number of foreign countries. Several radio manufacturers are now actively engaged in the manufacture of ground and aircraft radio equipment for use with this system. Information has been received that a number of the foreign countries are planning experimental installations. It is hoped that service tests of the system in this country will begin in the near future.

\section{ACKNOWLEDGMENTS}

In conclusion the author wishes to acknowledge the parts played in this development by his coworkers in the Bureau of Standards and in the Aeronautics Branch. Appreciation is due F. W. Dunmore for basic contributions during the development of the system and to G. L. Davies for research in the design and operation of the landing beam transmitting and receiving equipment.

Special appreciation is due Pilot M. S. Boggs for basic contributions to the practicability of the system during the tests at College Park. These tests were begun when there was still but little use and knowledge of instrument flying. Mr. Boggs' unfailing enthusiasm and keen perception of the practical requirements for instrument landings were responsible for many modifications in the system. The experience in instrument flying gained by Mr. Boggs during the tests at College Park was also largely responsible for the adoption by the Department of Commerce of the Scheduled Air Transport Rating for air line pilots, effective January 1, 1933, which requires a thorough knowledge of instrument flying and of locating a given radio rangebeacon station or any one of its courses in hooded flight tests.

Special acknowledgment is also due Pilot J. L. Kinney for valuable contributions and for skillful and courageous testing and demonstrations of the system at Newark. Mr. Boggs was killed while on other air-line duties in the southwest during the period of the installation work at Newark and Mr. Kinney, who served as check pilot during some of the tests at College Park, took up the test work at this point in a most satisfactory manner. Acknowledgment is also due $\mathrm{E}$. Yuravich for aid in serving as check pilot during the Newark tests.

Washington, August 1, 1933. 

